\title{
Cultural Background and Economic Development Indicators: European South Vs European North
}

\author{
P. E. Petrakis \\ Department of Economic Studies, National and Kapodistrian University of Athens, Athens, Greece \\ E-mail:ppetrakis@econ.uoa.gr \\ Received February 10, 2011; revised April 12, 2011; accepted April 26, 2011
}

\begin{abstract}
This paper examines the relationship between cultural background and economic development. We focus on the example of Greece in order to analyze the cultural disparities between the Mediterranean and the Northern European countries. We find that there is a common cultural model characterizing the Southern European nations, which spans the Mediterranean coast, from Portugal to Turkey. These countries are characterized by high uncertainty and absence of future orientation. On the other hand the cultural background in Northern European countries is found on individualism. The paper shows that the cultural values model is mirrored in the basic traits characterizing the economic and business environment of the areas (North-South) under examination. The differential cultural background is reflected in the basic economic and social developmental indicators in a consistent way.
\end{abstract}

Keywords: Cultural Background, Economic Development, Growth and Culture

\section{Introduction}

Discourse into the role of cultural values in the formation of a society's economic model, its growth and development has its roots in the ancient Greek authors in an effort to explain economic reality through human behaviours. The crucial question raised from this discourse is whether the existing social model promotes or deters growth and development and whether its evolution follows a favourable course for growth.

Within the European Union, Southern European countries, and particularly the Greek economy, systematically present macroeconomic characteristics, such as public over-indebting and a greater propensity to consume, that contrast markedly with Scandinavian economies. These characteristics have brought about higher standards of living, however at a future cost; i.e. loss of welfare for the generations to come. Other notable features of these economies are the absence of production and investment initiatives in innovation, high levels of self-employment, etc. A macroeconomic behaviour can be considered irrational if certain attributes are not repeated systematically. If certain economic decisions are repeated, they cannot be classified as "mistakes", since economic agents act "rationally" and are not myopic by assumption. What could be happening in this case is that economists interpret these decisions in the wrong context. In other words, the background information and assumptions made for the purposes of interpreting the macroeconomic environment are not the appropriate ones. Therefore, certain forces within those societies are systematically influential and contribute in the formation of economic phenomena. We speculate that such forces are strongly related with the structure of the specific cultural background and the long-term development model of these societies.

This issue is particularly timely after the 2008 financial crisis. The main characteristic of the over-indebted countries that were hit by the crisis is the government inability to aggressively intervene by further increasing the deficit, in order to cover the "potential production gap". The study of economic forces deriving from cultural values cannot help form short-term intervention schemes, since cultural norms are shaped under long-run influences. Thus, a deeper understanding of those cultural values is necessary for the assessment of the efficacy of short-term policy goals and the elaboration of an efficient long-term development strategy.

The rest of the article proceeds as follows: Section 2 discusses the cultural dimensions that we are focusing on, in this paper. Section 3 presents some preliminary evidence for the cultural differences between Northern and Southern European countries. Section 4 presents, in detail, 
the dominating cultural model in the Greek society. Last, Section 5 concludes.

\section{Context of Culturality}

Hofstede contributes to the valuatory, international comparative research literature in the following way $[1,2]$. He comes up with a set of values which can be used to measure a country's cultural background. Hofstede argues that these valuatory dimensions describe humanity's problems, present in all societies [3]. Countries have different scores per dimension demonstrating that various societies handle these problems differently. Hofstede identifies four dimensions, which pertain to: power distance (i.e. the acceptance of inequalities), uncertainty avoidance, individualism in opposition to collectiveness, and masculinity in opposition to femininity [4].

The Global Leadership and Organizational Effectiveness (GLOBE) study, conducted in the mid 1990s, adds to Hofstede's culture dimensions [5,6]. This research aims to explore the relationship between social culture, organisational culture and practice, and organisational leadership. The GLOBE study establishes nine dimensions of social culture that reflect society perceptions of medium-ranged managers, and their preferences on desired social traits. These dimensions are: power distance, uncertainty avoidance, institutional collectiveness (Collectiveness I), intra-group collectiveness (Collectiveness II), gender equality, imposition, future orientation, effectiveness orientation, and human orientation. Those dimensions resulted from bibliographic research on a vast sample of studies on culture measurement and the existing intercultural theory [7-11].

Table 1 presents the dimensions of social culturality in light of existing research. The dimensions described in points 1 through 4, derive from Hofstede's respective dimensions [12]. The first three correspond to power distance, uncertainty avoidance, and individualism respectively. Point 4 relates to the dimension of masculinity. In Table 1, the role of religious background is mentioned as a separate dimension. Religious background is not a different value per se, since its influence expands over the whole valuatory background. However, it is addressed here due to lack of in depth examination and analysis of religion within the Greek society.

Many researchers have concluded that religion creates and influences personal values and mentalities [13]. For instance, according to Weber [14], individualism, preference in personal choice and autonomy, and pursuing personal objectives are distinct features of Protestantism. By contrast, Confucianism is family- and group-oriented, shows respect for age and hierarchy, prefers harmony, and avoids conflicts and competition.

According to Weber, the Protestant "moral" plays a significant role, since it emphasises the tireless, endless acquisition of goods that was developed in some areas of Protestant Europe. Weber argues that Protestantism is the cradle of the modern economic person and that Calvinism, in particular, has accentuated individualism, personal potential, and initiative.

Even though modern capitalism was the result of the social structure in the Western world, it would have been inconceivable without Calvinism's contribution to freeing the acquisition of goods from the restrictions of traditional morality [15].

The connection between cultural values, stemming from the influence of the Orthodox Christian doctrine, dominating roughly $90 \%$ of the population of Greece and other Balkan countries for almost two millenniums, and economic activity has not been sufficiently examined.

Table 1. Dimensions of social culturality.

(1) Power distance (Acceptance of Inequalities)

(2) Uncertainty Avoidance

(3) Individualism vs Collectiveness (3.1) Institutional Collectiveness

(Collectiveness I)

(Collectiveness II)

$\{$ (3.2) Intra-group Collectiveness

(4) Masculinity vs Femininity (4.1) Gender equality

(4.2)Imposition

(5) Confucian Dynamism/ Future Orientation

(6) Efficiency- orientation

(7) Human orientation

(8) The role of Religion 
One of the rare sources examining this connection is $\mathrm{H}$. Economou [16]. It is worth mentioning the author's approach to religious beliefs, which are holistic and "comprise principles that produce or inspire economic theory and practice" (p. 150). An essential element of the Orthodox religious approach is that humans are not rulers of the natural world but rather users and managers. Additionally, all "goods to be managed" (knowledge and material goods) come from the outside (from God) and are free: They are "divine trusts". In Orthodox writings, there are no specific negative references to profit, but the tendency to maximise profit is strongly criticised. The personal benefit of the giver and responder to anyone's particular needs is not of material nature but rather of "moral and psychological nature" [17]. Thus, "the business activity is the opposite of religious, spiritual activity, which pursues the theoretical and experiential approach in the life issues. The activity of the human spirit comes first, prepares and leads the course of the economic activity" [18].

Based on these observations, it is understandable that the Orthodox Christian perception is not favourable to the notion of property, since according to this perception there are no belongings and nothing comes from the material world. If material goods are not at the centre of the cultural background, then we are drifting away from the logic of accumulation and therefore from the procedure of growth. At the same time, the Orthodox doctrine seems to move in an opposite direction from the process of profit maximisation, which is the necessary motive for activat- ing the economy and the growth process.

\section{Empirical Indications for Ranking Cultural Values}

Table 2 presents the ranking of Greece and selected Mediterranean and Northern European countries for each of the culturality dimensions, according to the Hofstede [19] and the GLOBE study criteria [20]. Hofstede's utilized a sample of 53 countries, whereas GLOBE used 61 countries. The GLOBE scores refer to practices (as is) and not to values (as it should be). The purpose of dividing the countries in our sample in two sub-groups is to make the cultural differences between the south and the north more apparent. The first group, the Mediterranean countries, is comprised of Spain, Italy, and Portugal, while the second group, the Northern European countries, is comprised of Denmark, the Netherlands, Sweden, and Finland.

Table 2 leads to the following conclusions:

1) On the issue of cultural values, Greece may be considered as a typical Mediterranean country in the sense that its ranking either places it within the limits of Mediterranean countries' rankings or very close to those limits.

2) Regarding the cultural indicators there is a clear distinction between the two groups, i.e. the Mediterranean and Northern European countries.

Hofstede and GLOBE deliver similar rankings for the two groups of countries. Nevertheless, it is necessary to

Table 2. Ranking of: greece, mediterranean and northern europe countries as to the dimensions of social culturality, based on the hofstede and GLOBE researches. Data coming from hofstede are marked with H; the GLOBE data bear no identification sign.

\begin{tabular}{|c|c|c|c|}
\hline Dimensions/Countries & GREECE & $\begin{array}{l}\text { MEDITERRANEAN } \\
\text { COUNTRIES }\end{array}$ & $\begin{array}{l}\text { NORTHERN EUROPE } \\
\text { COUNTRIES }\end{array}$ \\
\hline \multirow{2}{*}{ (1) Power Distance (Inequalities Acceptance) } & $27(\mathbf{H})$ & $24-34(\mathrm{H})$ & 40 - $51(\mathrm{H})$ \\
\hline & 21 & $15-20$ & $47-60$ \\
\hline (2) Uncertainty Avoidance (According to Hofstede) & $1(\mathrm{H})$ & $2-23(\mathrm{H})$ & $31-51(\mathrm{H})$ \\
\hline (3) Individualism vs. Collectiveness & 30 (H) & $7-33(\mathbf{H})$ & $4-17(H)$ \\
\hline 3.1 Institutional & 61 & $46-56$ & $1-20$ \\
\hline 3.2 Inta-group & 35 & $26-41$ & $54-60-$ \\
\hline (4) Masculinity vs. Femininity & $18(\mathrm{H})$ & $4-45(\mathrm{H})$ & $47-53(\mathrm{H})$ \\
\hline 4.1 Gender equality & 29 & $15-52$ & $5-31$ \\
\hline 4.2 Imposition & 60 & $11-46$ & $1-18$ \\
\hline (5) Confucian Dynamism Time orientation & 51 & $37-56$ & $4-14$ \\
\hline (6) Efficiency-orientation & 61 & $37-55$ & $19-48$ \\
\hline (7) Human-orientation & 59 & $41-60$ & $14-38$ \\
\hline
\end{tabular}


comment on the ranking for the uncertainty avoidance dimension. The GLOBE research presents several different results on the uncertainty avoidance dimension when compared to Hofstede's findings: Mediterranean countries have a lower ranking, implying lower uncertainty avoidance levels. The explanation might lie in the fact that Hofstede did not include Central and Eastern European countries in his sample. Additionally, the two studies used different measurement means in order to render this dimension operational [21]. Veneik and Brewer report 14 correlations between Hofstede's and GLOBE's measures of cultural values [22]: five variables are statistically significant and bear the expected sign (positive), eight bear the expected sign but are not statistically significant, and for one (uncertainty avoidance) there is a large negative and statistically significant correlation between the two measurement ways, which is strongly unexpectes. These two studies are similar in the social culturality dimensions they develop, except for "uncertainty avoidance". Generally, the two studies are similar in the rankings they create between societies, except for the "uncertainty avoidance" dimension. Veneik and Brewer are also concerned with this issue and in particular with the disparate findings for Greece and Portugal [23]. They base their interpretation of these disparities on the time difference (two decades) between the two studies. However, this interpretation does not sound convincing due to the slow pace characterizing behavioural and cultural changes. The authors rightly note that the two studies measure opposing concepts. This is due to the nature of the questions of the surveys themselves. The present study adopts Hofstede's measurement of "uncertainty avoidance" because it is compatible with the risk measurements (see Table 3.2, lines 2, 3 and 4) which prove that the Mediterranean countries have always been characterized by systematically higher risk levels. This fact justifies the formation of chronic risk avoidance behaviours.

The model of cultural values formed in the two groups of countries is roughly the following: Mediterranean countries accept more widely the existence of greater inequalities and (according to Hofstede) and demonstrate higher rates of uncertainty, when compared to Northern European countries. Individual achievements are not highly appreciated and at the same time the socially established organization rules and practices are not acceptable. Nevertheless, individuals express pride, faith, and cohesion with their families and any specific social group they belong to. Feminine values, such as quality of life, care for the weak, and solidarity play a small part and are characteristic features of Northern European countries. Accordingly, the values of imposition and of dispute do not seem to prevail.
The Mediterranean countries examined here are characterized by limited future orientation, lack of scheduling and long-term planning and portray low efficiency and human orientation levels while their main focus is on short-term planning.

\section{Synthesis on the Cultural Model of Greek Society and Economy}

Greece exhibits sociocultural traits similar to those of other Mediterranean countries. The formation of a social model for the Mediterranean as well as for Scandinavia is primarily based on common elements shared by the members of each group of countries (geography, evolution, history, etc.).

\subsection{Basic Description of the Model}

The cultural model of Greece consists of a synthesis of priorities. Despite the existence of a high degree of inequality in areas such as wealth, revenue, and power in Greece, the general feeling is disapproving of inequalities. It is characteristic that the GINI indicator (Table 3.1, line 2) for Greece, and the Mediterranean countries in general, is significantly higher (indicating a more unequal distribution) compared to that of the Northern European countries.

The degree of uncertainty avoidance is high, while the risk levels experienced by the social model are also large. It is worth mentioning that all risk indicators-total risk, political risk, and economic risk (Table 3.2, lines 2, 3, 4)-are higher (lower indexes) in the Mediterranean countries than the Northern European countries. In addition, fear of crime is much more intense in Mediterranean countries (see Table 3.2, lines 6, 7), compared to Scandinavia, although Mediterranean countries experience considerably lower crime rates. Fear of crime has an inverse prevalence, demonstrating that these countries "are worried" and "scared" about the present and the future.

Regarding future-orientation rankings, Greece is in the 51 st place, a considerably low point among the 61 countries included in the sample. This fact points to poor use of long-term planning. This implies that in general, there is a short-term perspective in the country and poor use of programming and long-term planning. The individualization of effort and the value of individual achievements are of low priority. The society does not encourage or reward its members adequately or according to their performance, while other indicators show that Greeks point to the need for wider recognition. According to Papalexandris there is a general trend of mistrust in individual achievements and high success levels [24]. Com- 
Table 3.1. Economic indicators.

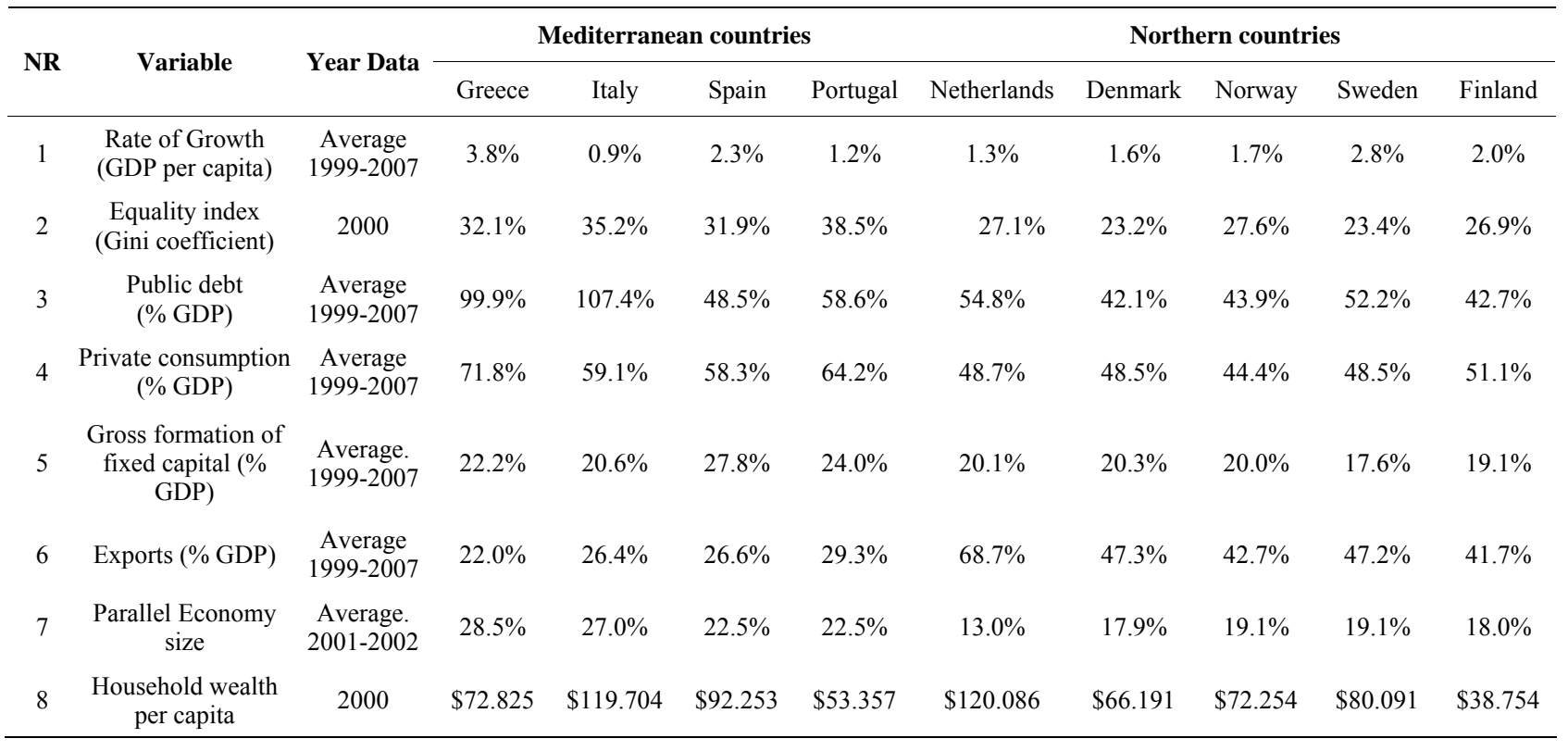

petition is usually combined with individualism, a tendency to mistrust, difficulty sharing responsibilities or combining efforts in order to achieve a common goal, and constant disputes over facts or ideas.

It is worth noticing the lack of efficiency orientation in the Greek society. The introduction of evaluation procedures (quality assurance and transparency) at all levels of education has not been fully implemented. Accordingly, public acceptance of entrepreneurship seems to be moving to lower levels in the Mediterranean countries than in the Northern European countries, except for Denmark (Table 3.2, line 14).

In Greece as well as in other Mediterranean countries, trust in institutions and participation in collective procedures is particularly low (see Table 3.2, line 7). On the other hand, intra-group collectiveness recognized mainly within families (a form of institution), is strongly represented in the Greek society. According to a Eurobarometer study on European society, $100 \%$ of Greeks believe that family is the most important social institution [25]. This fact explains to a large extent the low attendance rates of children in infant care in the Mediterranean region when compared to Northern Europe (Table 3.2, line 9). According to Triandis intra-group collectiveness pertains to differences between an attitude towards a member of a group and an attitude towards a non-member [26]. The group may include immediate family, relatives, and friends. Its members enjoy protection, trust, and support in exchange for their faith, devotion, and sacrifices. However, non-members are treated with suspicion and hostility.

In Greece the majority of firms are family businesses.
Georgas reports that intra-group collectiveness has significantly influences the way Greek companies are organized and managed [27]. Even in cases where the company grows in size and activities, the owner-director recruits people from his direct environment, such as immediate family, other relatives, and friends, rather than specialized professionals that he doesn't personally know [28]. It is suggested that the particularly slow development of Greek businesses is highly attributable to the coincidence of ownership and management $[29,30]$.

Greece has a "masculine" social organization which is developing in the absence of social solidarity and care for the weak. Consequently, it is not surprising that there is poor orientation towards human needs. A world full of uncertainty and reduced collective trust leads to the acquisition of individual wealth as the ultimate form of security. It is worth noting that the level of individual wealth in Greece is higher than in Denmark and is comparable to that of Norway (Table 3.1, line 8). Generally, the levels of individual wealth in Northern European countries are lower than those in Mediterranean countries. The citizens of Northern European countries live more "happy life years" (Table 3.2, line 1) using services that improve quality of life and are not necessarily related to individual wealth levels. Nevertheless, in the North there is rejection of the value of imposition and poor encouragement for competition in social relationships. Similarly, "feminine values" in the Mediterranean countries are weak. An example of that is the concern about environmental quality, which is substantially different between Mediterranean and Northern European countries (see Table 3.2, line 17). 
Table 3.2. Developmental indicators.

\begin{tabular}{|c|c|c|c|c|c|c|c|c|c|c|c|}
\hline \multirow{2}{*}{\multicolumn{2}{|c|}{ Variable }} & \multirow{2}{*}{ Year } & \multicolumn{4}{|c|}{ Mediterranean Countries } & \multicolumn{5}{|c|}{ Northern countries } \\
\hline & & & Greece & Italy & Spain & Portugal & Netherlands & Denmark & Norway & Sweden & Finland \\
\hline 1 & "Happy life years"”*1 & 2008 & 50.4 & 54.4 & 57.8 & 44.0 & 59.1 & 65.4 & 61.7 & 62.2 & 69.0 \\
\hline 2 & Total Risk ${ }^{* 2}$ & 2007 & 72.2 & 77.2 & 77.5 & 77.5 & 85.0 & 86.5 & 92.2 & 87.2 & 88.2 \\
\hline 3 & Political Risk $^{*_{3}}$ & 2007 & 77 & 79 & 80 & 83 & 84.5 & 85.5 & 89.5 & 88.5 & 94 \\
\hline 4 & Economic Risk $^{* 4}$ & 2007 & 35.5 & 39.0 & 39.5 & 35.5 & 45.0 & 44.0 & 48.0 & 46.0 & 46.0 \\
\hline 5 & Criminality $^{* 5}$ & 2004 & 12.3 & 12.6 & 9.1 & 10.4 & 19.7 & 18.8 & 15.8 & 16.1 & 12.7 \\
\hline 6 & Fear of Criminality ${ }^{* 6}$ & 2004 & 42 & 35 & 33 & 34 & 18 & 17 & 14 & 19 & 14 \\
\hline 7 & $\begin{array}{l}\text { Confidence in national } \\
\text { institutions }{ }^{* 7}\end{array}$ & 2006 & $-16.0 \%$ & $-31.0 \%$ & $-8.0 \%$ & $-23.0 \%$ & $1.0 \%$ & $7.0 \%$ & - & $3.0 \%$ & $30.0 \%$ \\
\hline 8 & Participation in groups ${ }^{* 8}$ & $1999 / 2000$ & $8.9 \%$ & $23.8 \%$ & $24.5 \%$ & $18.0 \%$ & $44.8 \%$ & $65.1 \%$ & & $40.9 \%$ & $55.2 \%$ \\
\hline 9 & $\begin{array}{l}\text { Participation percentage of } \\
\text { children }(<3 \text { years }) \text { in } \\
\text { organized infants' care units }{ }^{* 9}\end{array}$ & 2005 & $7.0 \%$ & $6.3 \%$ & $20.7 \%$ & $23.5 \%$ & $29.5 \%$ & $61.7 \%$ & $43.7 \%$ & $39.5 \%$ & $22.4 \%$ \\
\hline 10 & Corruption index ${ }^{* 10}$ & 2008 & 4.7 & 4.8 & 6.5 & 6.1 & 8.9 & 9.3 & 7.9 & 9.3 & 9 \\
\hline 11 & Owner occupancy dwelling ${ }^{* 11}$ & & $\approx 80 \%$ & $\approx 72 \%$ & $\approx 80 \%$ & & $\approx 50 \%$ & $\approx 65 \%$ & & $\approx 65 \%$ & \\
\hline 12 & Employment $^{* 12}$ & 2007 & $61.5 \%$ & $58.7 \%$ & $66.6 \%$ & $67.8 \%$ & $74.1 \%$ & $77.3 \%$ & $77.5 \%$ & $75.7 \%$ & $70.5 \%$ \\
\hline 13 & $\begin{array}{l}\text { Entrepreneurship } \\
\text { acceptance }^{* 13}\end{array}$ & 2007 & $65.9 \%$ & $68.5 \%$ & $61.0 \%$ & $67.2 \%$ & $68.8 \%$ & $79.1 \%$ & $56.6 \%$ & $67.4 \%$ & $84.8 \%$ \\
\hline 14 & 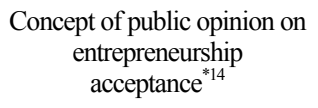 & 2007 & $43.4 \%$ & $43.9 \%$ & $45.5 \%$ & $51.2 \%$ & $61.1 \%$ & $35.5 \%$ & $69.5 \%$ & $62.8 \%$ & $68.3 \%$ \\
\hline 15 & $\begin{array}{l}\text { Rating of the business activity } \\
\text { framework }^{* 15}\end{array}$ & 2009 & 96 & 65 & 49 & 48 & 26 & 5 & 10 & 17 & 14 \\
\hline 16 & Governance Efficiency ${ }^{* 16}$ & 2007 & 70 & 65 & 81 & 80 & 95 & 99 & 100 & 98 & 98 \\
\hline 17 & $\begin{array}{l}\text { Gas emissions (millions in } \\
\mathrm{CO} 2 \text { equivalents) }{ }^{* 17}\end{array}$ & 2007 & 131.85 & 552.77 & 442.32 & 81.84 & 207.5 & 66.64 & 55.05 & 65.41 & 78.35 \\
\hline
\end{tabular}

*1: Estimates how long and how happily people of each country will live [36]. *2: The index of total risk is a calculation of separate risk indicators (economic, financial, political, etc.) and its values are from 0 to 100 . When the index increases it means the risk levels of a country are reduced and vice versa. Source PRS Group, ICRG database. *3: The index of political risk is a calculation of separate measurements of political risk (for instance internal and external conflicts, quality of public administration, corruption, etc.) and its values are from 0 to 100 . When the index increases it means the political risk in a country is reduced and vice versa. Source: PRS Group, ICRG database. *4: The index of economic risk is a calculation of separate indicators of a country's economic situation (for instance growth rate, inflation levels, balance of current transactions and budget, public debt levels, etc.) and its values are between 0 and 50 . When the index increases it means the economic risk in a country is reduced and vice versa. Source: PRS Group, ICRG database. *5: The index shows the population percentage reporting criminal acts. Source: OECD, Society at a glance, 2009. *6: The index shows the population percentage expressing fear of walking the streets after sunset. Source: OECD, Society at a glance, 2009. *7: Positive minus negative opinions on the national institutions. Source: Eurobarometer 66 (2006). *8: Source: European Values Study 1999/2000. *9: Source: OECD, Society at a glance, 2009. *10: The Corruption Perception Index is drown by calculating separate indexes from answers in questionnaires by people with knowledge on the relevant subjects. Source: Transparency International, 2008. *11: Source: French Statistics' Agency (www.insee.fr). *12: Source: OECD, Society at a glance, 2009. *13: Percentage of positive answers in a question about accomplishment and respect towards those who establish a new business successfully [37]. *14: Percentage of positive answers to a question on promoting success stories of new businesses, by the media [38]. *15: The index is an indication for business facilitation and derives from calculation of separate indexes (for instance, facilitation in new business establishment, recruitment of partners, obtaining credits etc). Source: World Bank, Doing Business. *16: The governance efficiency index derives from statistical processing of questionnaire answers given by citizens, company employees, and experts in related fields. Its value is between 0 and 100 . The higher values mark governance efficiency and vice versa. Source: World Bank, Governance Indicators, 2007. *17: Source: Eurostat, env_air_emis, GHG

\section{2. "Old" and "New" Societies}

In the Greek economy cultural values are not just present but also strongly felt. It is worth comparing Greek and Scandinavian societies focusing on the four basic values, Power Distance (PDI), Individualism (IDV), Masculinity (MAS) and Uncertainty Avoidance (UA) [31]. The sum of all points for the Scandinavian countries is 140, while for Greece it is 269. Of Scandinavia's 140 points, 69 account for the value of individualism (IDV).

The strength of the Greek results indicate that in Greece (which is not different, as seen, from other Mediterranean countries) there is an active cultural background that could potentially benefit growth and development. However, the exact opposite result occurs if culture is not conducive to that direction. We claim 
that the societies of the South have a "strong subconscious" as "old" societies. On the other hand, northern societies are "new", lack a firm background, and are therefore more open to cultivation of modern values that provide them a satisfactory level of happiness. It is worth noticing that in the "happy years of life" index (that is the combination of satisfaction with life according to the Gallup World Poll and life expectancy) the Northern European countries have a lead of almost a decade compared to the Mediterranean countries (Table 3.2, line 1).

\subsection{The Basic Difference between the Two Models}

The difference between Greece and Scandinavia derives from two values. For Greek society this value is uncertainty avoidance, and for Scandinavia it is the importance of individualism. These factors determine the vitality of growth and development processes.

Morris et al. connect the dimension of individualism with entrepreneurship [32]. They focus on the concept of individualism in relation to the level of incitement for achievements and the desire to breach the rules connected to entrepreneurial action. Hofstede observed equivalence between economic indicators, such as per capita GDP, and the dimension of individualism [33]. Although the positive correlation between the two is not evidence of causation, societies with a high individualism index and low power distance index present higher economic growth and stronger tendencies for innovation. This fact is also confirmed by Shane [34].

Uncertainty avoidance in practice orients the social model away from entrepreneurship (Table 3.2, line15) but is able to cover survival needs through "secure" employment positions, i.e. in the public sector. It is remarkable that approximately $27.4 \%$ (or $1,250,000$ workers) of the Greek labor force is employed in the public sector, either as permanent employees $(60 \%)$ or as contract servants (40\%). Lack of individualisation and recognition of personal achievements are among the most important features of the prevailing cultural values model. Serious discourse regarding the lack of these two values in the Greek society took place between 1995 and 2005. The most crucial contribution to this matter was done by Ramfos in an attempt to relate the value of individualization with its substitution by the constant reference to the "state entity" [35]. The establishment of the significance of state entity in social conscience should also be attributed to the historical evolution of the neo-Hellenic society, in combination with high risk levels in the economy. Besides, the acceptance of power distance in the Greek society favours in particular the dominance of the state, in the operation of which the citizens do not bear the direct costs and at the same time are relieved from decision-making responsibilities. These features led to 1) the formation of a strong bureaucratic management (requiring multiple approval signatures), 2) the absence of personal responsibility in business successfulness, and 3) lack of methods of control and evaluation of personal activity, that lead to poor efficiency orientation. As a result, Mediterranean countries are rated lower than Northern European countries in governing efficiency (Table 4.2, line 16).

At a first glance we observe a controversial correlation between institutional entity and institutional collectiveness, which however, can be intuitively explained in the following way. Lack of strong individualism in the Greek society is not due to its replacement by organized collectiveness (where the person participates with responsibilities), but rather by a transcendent entity (that resembles the divine ownership of the Orthodox doctrine) that acts instead of the person.

The existence of such an entity a priori acts as an obstacle to the motivation for entrepreneurship in the sense that "it is not needed" and eventually "not approved", especially when it requires tying up resources for a considerable period of time.

The second level of individual protection (after the invocation of the state entity) is the promotion of intra-group collectiveness, mainly comprising human and social networks. As a cultural value, intra-group collectiveness does foster the operation of the labor market because it blocks important work forces. However, at the same time it produces unusual levels of trust and social cohesion. These two values are present in local markets, however remain absent when a market is globalizes. Consequently, the expectation of economic extroversion is confirmed (see Table 3.1, line 4).

Individualization and "denial" of institutional collectiveness in combination with promotion of "masculinity" (aggressiveness) result in a non-regulated market operation, an example of which is the development of a parallel economy and economic delinquency. The Mediterranean countries demonstrate higher rates of parallel economy (as a GDP percentage, see Table 3.1, line 5) while the corruption index take lower values (indicating higher corruption levels, see Table 3.2, line 11,) in the Mediterranean countries compared to Northern European countries.

\subsection{Time Orientation and the Future}

Hofstede and Bond showed that the measure of future orientation and of delayed gratification named Confucian Dynamism is positively related to the economic growth of the Asian Tigers from 1968 to 1985 [39]. Dornbusch 
et al. comment on the economic miracle of those countries, underlining that hard work, sacrifices, education, savings, and investment relate to economic growth [40]. Societies with members that sacrifice immediate consumption for future consumption should experience faster growth.

Using the database of the World Values Survey (2006), Minkov and Blagoev point out that cultures demonstrating high savings rates show for the most part small interest in entertainment, family, and contribution to their fellow men [41]. The pessimism observed in Greek society is connected to the lack of future orientation. More specifically, in Greece we observe a strong pessimism for the future, expressed by high percentages of people who think that the economic situation and employment will only deteriorate (55\% and 59\% respectively) [42]. A study of the Eurobameter data surveys on the European Union public opinion for the years 2001 and 2008 leads to the conclusion that there is a progressively decreasing number of Greek citizens who expect progress in social issues [43-48].

It is extremely difficult to understand whether pessimism and the lack of future orientation are related in a causal manner or if the two simply coexist having different generating causes. Such a cause would be the social understanding of the potential of the development model, which is limited. Another cause, however, could be the gap between the actual life of a person as compared to the perception of the real possibilities at his disposal. It should be noted that this pessimism is also abundant in other Southern European countries and less so in Northern European countries. However, these values evidently drive people away from saving and investing and therefore away from growth, while pushing towards consumption (see Table 3.1, line 3). Consumption as a GDP percentage is higher in the Mediterranean countries than in Northern Europe. The lack of future orientation is equivalent to macroeconomic behaviours expressed through political parties and governments as global social perceptions. The constant presence of public deficits in national accounts implies a strong preference for the present rather than the future (see Table 3.1, line 2). Public deficit as a percentage of GDP in the Mediterranean countries is higher than in Northern European countries. This is another significant drawback of the Greek managerial malpractices due to lack of strategic long-term planning [49]. Makridakis et al. argue that the lack of long-term planning is a result of i) increased uncertainty for the future, ii) frequent legislative amendments, and iii) unpredictable facts that force Greek managers to restrict themselves to short-term planning [50].

The lack of future orientation is also obvious in the existence of high uncertainty levels that correlate with the observation that the most preferable investment for Greeks (and for other Southern Europe countries) is to "have a roof over your head", i.e. to invest in homes. Greece presents one of the highest owner-occupancy dwelling rates in the measurable world (see Table 3.2, line 12). Additionally, in a world of uncertainty and a lack of respect towards institutional collectiveness, and the services provided by this collective entity, it is reasonable to make efforts to expand personal wealth as a means to secure the individual and his/her family from the "hostility of the outside world".

\subsection{Self-Employment and Parallel Economy}

Promotion of self-employment and the lack of creative entrepreneurship are highly related with 1) the degradation of personal achievements, 2) the downgrading of the value of profits in conjunction with the promotion of competitiveness, and 3) the lack of faith in collective work.

Self-employment has its roots in the lack of employment opportunities in the public sector, which is usually the first employment choice in the Greek society, as well as the private sector. "Masculinity" is expressed through personal independence that goes along with self-employment. At the same time the individual tackles the risks of the liberal profession using his personal networks. Consequently, a big proportion of the Greek labor force is self employed (see Table 3.2, line 12). Future uncertainty and the resulting reluctance to tie up capital in business development contributes to higher self-employment levels.

From a cultural point of view, the parallel economy expansion results from the coincidence of a number of values. The lack of trust in institutions, combined with the dominance of intra-group collectiveness, and the rejection of institutional collectiveness play the most significant role. However, at the same time, an equally important role is played by the poor future orientation, including the pessimism that prevents tying up resources. In this view, an unwillingness to participate in the cost carried by the society (tax evasion) is acceptable, followed by the over-indebting of the "other entity" (the state) that maintains the "inexpensive" improvement of the living standard, while increasing the opportunities to expand personal wealth. The parallel market delinquency is cultivated by the masculinity background. Under these circumstances, entrepreneurship develops by "extracting" legitimacy from the state entity in a process of conflict between the two powerful actors (businessmen and the state entity). 


\subsection{The Role of Religion}

The social model described above is influenced by the religious background (the Orthodox doctrine for the Greek economy), whose role is independent of significant driving forces of growth (ownership and accumulation, the maximisation of profit). This conclusion is based, not on the spiritual context of the doctrine (which is rather negative on some issues), but rather on the lack of will of the Orthodox Church to intervene in everyday economic life. The Church's practice in some areas of economic reality (asset management, Church of Cyprus, etc.) confirms this point of view. We note that in the Orthodox doctrine there are no ideological promotional factors present in other religious beliefs, such as Protestantism and Confucianism.

\subsection{The Mediterranean vs Northern European Model}

A particularly interesting observation is that the cultural value model found in Greece is common in almost all Mediterranean countries and has specific differences from the Scandinavian model. Let us explore the forces that have interacted or still interact in the Mediterranean societies forming homogenous value standards. Geography, for instance, plays an important role. In the case of Greece, geography relates to the temperature, the sea, and the geological proximities. These proximities pertain to the distance from technology production and innovation centers of Central and Western Europe as well as the proximity with the Arab countries in the South and Turkey in the East. Additionally, in the Balkans there are strong Arab influences, and the cultural influence borders are indistinguishable. Within the last two millenniums, this proximity involved a constant influence and frontier redistribution process. The main feature of these redistributions was their permanent and irregular character (repeated invasions, piracy in the Mediterranean, etc.). During the last two millenniums in Northern Europe conflicts occurred along with constant changes in frontiers. Perhaps the risk presented in South Europe had a sense of "total" disaster due to the cultural conflict. This conflict, unlike the case of Northern Europe, was not characterised by unequal distribution of regions with economic influence.

A simple comparison of the cultural value systems (as Hofstede puts them) in Scandinavian, the Mediterranean, the Arab countries and ultimately in Turkey (Table 4) led to the following conclusions. The cultural models characterizing the Arab countries are almost identical.

The Turkish cultural model is closer to that of the Mediterranean region. In terms of cultural values and for
Table 4. Cultural models in Scandinavian countries, in the Mediterranean, in the Arab World and in Turkey.

\begin{tabular}{lcccc}
\hline & PDI & IDV & MAS & UA \\
\hline $\begin{array}{l}\text { Scandinavian Countries } \\
\text { (Norway, Sweden, Denmark, }\end{array}$ & 24 & 65 & 9 & 38 \\
$\begin{array}{l}\text { Finland) } \\
\text { Greece }\end{array}$ & 60 & 35 & 57 & 112 \\
Italy & 45 & 70 & 63 & 70 \\
Spain & 52 & 45 & 38 & 80 \\
Portugal & 58 & 20 & 25 & 98 \\
$\begin{array}{l}\text { Turkey } \\
\begin{array}{l}\text { Arab World } \\
\text { (Egypt, Iraq, Kuwait, Lebanon, } \\
\text { Libya, Saudi Arabia, UAE) }\end{array}\end{array}$ & 80 & 38 & 52 & 68 \\
\hline
\end{tabular}

the purposes of future research in this area, we argue that it is evident to re-define the South European region to include all countries from Portugal in the West through Turkey in the East. This is due to the common cultural factors present in these countries.

In addition, the Mediterranean model resembles more that of the Arab nations than the Scandinavian ones. Hence, we arrive at the conclusion that the determinants of the cultural models characterizing the Mediterranean and the Arab region are similar, however in the Mediterranean these forces had a smaller impact over time. These forces can be identified among the founding components of Western civilization, i.e. religion and climate. Given the above we conclude that the existing cultural model in the Mediterranean countries is not the result of extreme and continuous conflict but rather, the result of an endless, constant mix of cultural models in the area which took place under the interaction of common primary forces, identified above.

\section{Conclusions}

This article provides a description of the cultural background of the Greek society and its impact on economic development. We also establish significant similarities in the cultural backgrounds of the Mediterranean countries, mainly characterized by uncertainty and pessimism about the future. On the other hand, the cultural background in Northern European countries is founded on individualism and does not heavily rely on the social values examined through the course of the present study; these values are however central in the Southern European cultural model. With reference to the contribution of culture to development and economic growth in Greece, one of the strongest aspects is intra-group collectiveness (that holds only for local business initiatives, whereas it has the op- 
posite effect when it comes to globalized initiatives). With regards to elements that impede economic development and growth in Greece, one can identify religion, low levels of individualism, high power distance, uncertainty avoidance, poor future orientation, and weak orientation towards individual needs.

\section{Reference}

[1] G. Hofstede, "Culture's Consequences: International Differences in Work-Related Values," Sage Publications, Beverly Hills, 1980.

[2] G. Hofstede, "Culture's Consequences-Comparing Values, Behaviours, Institutions and Organisations across Nations," 2nd Edition, Sage Publications, London, 2001.

[3] G. Hofstede, "Culture's Consequences: International Differences in Work-Related Values," Sage Publications, Beverly Hills, 1980.

[4] G. Hofstede, "Culture's Consequences: International Differences in Work-Related Values," Sage Publications, Beverly Hills, 1980.

[5] R. J. House, P. J. Hanges, S. A. Ruiz-Quintanilla, P. W. Dorfman, M. Javidan and M. Dickson, "Cultural Influences on Leadership and Organisations: Project GLOBE," In: Mobley et al. (eds), Advances in Global Leadership, 1 Greenwich, CT: JAI., pp. 171-233).

[6] R. J. House, P. J. Hanges, M. Javidan, P. W. Dorfman and V Gupta, "Culture, Leadership and Organisations-The GLOBE Study of 62 Societies," Sage Publications, Thousand Oaks, 2004.

[7] G. Hofstede, "Culture's Consequences: International Differences in Work-Related Values," Sage Publications, Beverly Hills, 1980.

[8] G. Hofstede and M. Bond, "The Confucius Connection: From Cultural Roots to Economic Growth," Organizational Dynamics, Vol. 16, 1988, pp. 4-21.

[9] F. Kluckhohn and F. Strodtbeck, "Variations in Value Orientation," Harper Collins, New York, 1961.

[10] D. C. McClelland, "The Achieving Society," Van Nostrand, New York, 1961.

[11] H. C. Triandis, "Individualism and Collectivism," Westview Press, Boulder, 1995.

[12] G. Hofstede, "Culture's Consequences: International Differences in Work-Related Values," Sage Publications, Beverly Hills, 1980.

[13] M. Tayeb, "National Cultural Characteristics," In: M. Tayeb, Ed., International Business Theories, Policies and Practices, Pearson Education Limited, Harlow, pp. 309335.

[14] Weber, Max, Protestant Ethic and the Spirit of Capitalism, 1905

[15] M Tayeb, () National cultural characteristics, in M. Tayeb (eds.), International business theories, policies and practices. Harlow, UK: Pearson Education Limited, 2000pp. 309-335.
[16] H. Economou, "Axioms and Principles of Entrepreneurship in Orthodox Christianity," In: P. Petrakis, Ed., Entrepreneurship, P. E. Petrakis, Athens, 2008, pp. 150-161.

[17] H Economou, () Axioms and principles of entrepreneurship in Orthodox Christianity. In P. Petrakis (Ed.), Entrepreneurship (pp. 150-161). Athens: P. E. Petrakis (in Greek) 2008.

[18] Economou, (2008) Axioms and principles of entrepreneurship in Orthodox Christianity. In P. Petrakis (Ed.), Entrepreneurship (pp. 150-161). Athens: P. E. Petrakis (in Greek).

[19] G. Hofstede, “Culture's Consequences-Comparing Values, Behaviours, Institutions and Organisations across Nations," 2nd Edition, Sage Publications, London, 2001.

[20] P. L. Koopman, D. N. Den Hartog, E. Konrad, et al., "National Culture and Leadership Profiles in Europe: Some Results from the GLOBE study," European Journal of Work and Organizational Psychology, Vol. 8, No. 4, 1999, pp. 503-520.

[21] Koopman, P. L., Den Hartog, D. N., Konrad, E. et al. (1999). National culture and leadership profiles in Europe: Some results from the GLOBE study. European Journal of Work and Organizational Psychology, 8(4), 503-520.

[22] S. Venaik and P. A. Brewer, "Contradictions in National Culture: Hofstede vs. GLOBE," In: J. Cantwell and T. Kiyak, Eds., Proceedings of the 50th Annual Meeting of the Academy of International Business, Italy, 2008, pp. 274-274.

[23] S. Venaik and P. A. Brewer, "Contradictions in National Culture: Hofstede vs. GLOBE," In: J. Cantwell and T. Kiyak, Eds., Proceedings of the 50th Annual Meeting of the Academy of International Business, Italy, 2008, pp. 274-274.

[24] N. Papalexandris, "Greece, from Ancient Myths to Modern Realities,” In: J. S. Chhokar, F. C. Brodbeck and R. J. Houseeds, Eds., Culture and Leadership, across the World: The GLOBE Book of in-Depth Studies of 25 Societies," Lawrence Erlbaum Associates, New Jersey, 2007, pp. 767-802.

[25] European Commission, "Special Eurobarometer No 273," 2006.

http://ec.europa.eu/public_opinion/archives/ebs/ebs_273 en.pdf

[26] H. C. Triandis, "Individualism and Collectivism," Westview Press, Boulder, 1995.

[27] J. Georgas, "Management in Greece," In: D. J. Hickson, Ed., Management in Western Europe: Society, Culture and Organisation in Twelve Nations, Walter de Gruyter, Berlin, 1993, pp. 109-124.

[28] S. Makridakis, Y. Caloghirou, L. Papagiannakis and P. Trivellas, "The Dualism of Greek Firms and Management: Present State and Future Implications," European Management Journal, Vol. 15, No. 4, 1997, pp. 381-402.

[29] S. Makridakis, Y. Caloghirou, L. Papagiannakis and P. Trivellas, "The Dualism of Greek Firms and Management: Present State and Future Implications" European Management Journal, Vol. 15, No. 4, 1997, pp. 381-402. 
[30] D. Bourantas and V. Papadakis, "Greek Management. International Studies of Management and Organisation," Vol. 26, No. 3, 1996, pp. 13-32.

[31] G. Hofstede, "Culture's Consequences-Comparing Values, Behaviours, Institutions and Organisations across Nations," 2nd Edition, Sage Publications, London, 2001.

[32] M. H. Morris, D. Sexton and P. Lewis, "Reconceptualizing Entrepreneurship: An Input-Output Perspective," SAM Advanced Management Journal, Vol. 59, No. 1, 1994, pp. 21-31.

[33] G. Hofstede, "Culture's Consequences: International Differences in Work-Related Values," Sage Publications, Beverly Hills, 1980.

[34] S. Shane, "Cultural Influences on National Rates of Innovation," Journal of Business Venturing, Vol. 8, 1993, pp. 59-73.

[35] S. Ramfos, "Chapters of Mental History of Greeks," Armos, Athens, 2000.

[36] R. Veenhoven, "World Database of Happiness, Bibliography, Internetsite: World Data Base of Happiness .eur.nl (2009).

[37] S. Ioannides and A. Tsakanikas, "Entrepreneurship in Greece, 2007-2008", Foundation for Economic and Industrial Research, IOBE, Athens, 2008.

[38] S. Ioannides and A. Tsakanikas, "Entrepreneurship in Greece, 2007-2008", Foundation for Economic and Industrial Research, IOBE, Athens, 2008.

[39] G. Hofstede and M. Bond, "The Confucius Connection: From Cultural Roots to Economic Growth," Organizational Dynamics, Vol. 16, 1988, pp. 4-21.

[40] M. Minkov and V. Blagoev, "Cultural Values Predict Subsequent Economic Growth," International Journal of Cross-Cultural Management, Vol. 9, No. 1, 2009, pp. 524.

[41] World Values Survey, "On-Line Data Analysis," Retrieved April 2009, 2006. http://www.worldvaluessurvey.com

[42] European Commission, "Special Eurobarometer No 273," 2006.

http://ec.europa.eu/public opinion/archives/ebs/ebs 273 en.pdf

[43] European Commission, "Standard Eurobarometer No $70, " 2008$.

http://ec.europa.eu/public opinion/archives/eb/eb70/eb70 en.htm

[44] European Commission, "Standard Eurobarometer No $68, " 2007$.

http://ec.europa.eu/public_opinion/archives/eb/eb68/eb68 en.htm

[45] European Commission, "Standard Eurobarometer No $66, " 2006$

http://ec.europa.eu/public opinion/archives/eb/eb66/eb66 en.htm

[46] European Commission, "Standard Eurobarometer No $62, " 2004$.

http://ec.europa.eu/public opinion/archives/eb/eb62/eb62 en.htm

[47] European Commission, "Standard Eurobarometer No $58, " 2002$.

http://ec.europa.eu/public opinion/archives/eb/eb58/eb58 en.htm

[48] European Commission, "Standard Eurobarometer No $54, " 2001$.

http://ec.europa.eu/public_opinion/archives/eb/eb54/eb54 en.htm

[49] B. Myloni, A.-W. Harzing and H. Mirza, "Human Resource Management in Greece: Have the Colours of Culture Faded Away?" International Journal of Cross-Cultural Management, Vol. 4, No. 1, 2004, pp. 59-76.

[50] S. Makridakis, Y. Caloghirou, L. Papagian Nakis and P. Trivellas, "The Dualism of Greek Firms and Management: Present State and Future Implications," European Management Journal, Vol. 15, No. 4, 1997, 381-402. 